Revista Tecné, Episteme y Didaxis: TED. Año 2014, Número

Extraordinario. ISSN Impreso: 0121-3814, ISSN web: 2323-0126

Memorias, Sexto Congreso Internacional sobre Formación de Profesores de Ciencias. 08 al 10 de octubre de 2014, Bogotá

\title{
Momentos pedagógicos no ensino de química: em foco a adulteração dos combustíveis
}

Costa, Lorenna Silva Oliveira', Ribeiro-Vilela Eveline Borges², Oliveira Bruna Rafaela Simões de ${ }^{3}$, Jesus, Elaine Francielle ${ }^{4}$.

Categoria 1: Reflexões e experiências de inovação na sala de aula.

\section{Resumo}

Apresentamos um projeto desenvolvido no Brasil, no Ensino Médio Integrado, com o tema "Adulteração de Combustíveis" estruturado sob o viés da educação problematizadora de Paulo Freire, com a estruturação de três momentos pedagógicos.

\section{Palavras chave}

Momentos pedagógicos; Contextualização; Ensino de química

\section{Introdução}

Diante dos problemas comumente enfrentados no processo de ensino e aprendizagem de ciências (Cachapuz et al., 2005) surgem propostas para a renovação do Ensino de Ciências, que visam a aproximação entre ciência e sociedade, a inclusão da investigação científica a aspectos políticos, econômicos e culturais e a valorização de conteúdos científicos com a finalidade de identificar problemas e propor soluções, conteúdos esses, próximos ao cotidiano.

Com base nessa reflexão, o objetivo desse trabalho é apresentar um projeto didático-pedagógico com o tema "Adulteração de Combustíveis" que foi estruturado a partir dos Momentos Pedagógicos proposto por Delizoicov (1991) e Delizoicov, Angotti e Pernambuco (2002).

\footnotetext{
1 Instituto Federal de Educação, Ciência e Tecnologia de Goiás - Câmpus Inhumas. lorennasocosta@gmail.com

2 Universidade Federal de Goiás - Regional Jataí. eveline_vilela@yahoo.com.br

3 Instituto Federal de Educação, Ciência e Tecnologia de Goiás - Câmpus Inhumas. brunasimoes16@hotmail.com

${ }^{4}$ Instituto Federal de Educação, Ciência e Tecnologia de Goiás - Câmpus Inhumas. elainefrancielly@hotmail.com
} 
Revista Tecné, Episteme y Didaxis: TED. Año 2014, Número Extraordinario. ISSN Impreso: 0121-3814, ISSN web: 2323-0126

Memorias, Sexto Congreso Internacional sobre Formación de Profesores de Ciencias. 08 al 10 de octubre de 2014, Bogotá

\section{Desenvolvimento}

\section{Educação problematizadora e momentos pedagógicos em sala de aula}

Com ênfase no pensamento de Paulo Freire sobre a educação problematizadora, podemos afirmar que essa consiste no desenvolvimento crítico e cognoscitivo do aluno tirando a ênfase da memorização e transferência excessiva de conteúdos (Freire, 2005). Com base nas ideias propostas por Freire sobre a problematização, Delizoicov (1991) e Delizoicov, Angotti e Pernambuco (2002) proporam três momentos pedagógicos importantes para a utilização em sala de aula, que estão classificados como:

I. Problematização inicial: são abordados temas vivenciais dos alunos, uma vez que o educador estabelece meios para auxiliá-lo a identificar o que os alunos sabem a respeito do tema proposto, para então propor questionamentos desafiadores sem dar respostas para tais perguntas. O objetivo desse momento pedagógico é de modo geral, estabelecer perguntas aos alunos que os façam pensar sobre determinado assunto e reconhecer que precisam obter novos conhecimentos para entender e propor soluções para o assunto em questão.

II. Organização do conhecimento: se estuda conhecimentos científicos a favor do entendimento do tema proposto pelo professor. Nesse caso, pode-se utilizar experimentação, vídeos, documentários e outras metodologias. Nessa etapa, é necessário trabalhar conteúdos envoltos ao tema.

III. Aplicação do conhecimento: o educador deve propor atividades para que os alunos apliquem os conhecimentos adquiridos na organização do conhecimento e nos questionamentos da problematização inicial. Nessa etapa, os educandos devem explicar não somente os aspectos que envolvem seu dia-a-dia, mas também explicações científicas.

Com base nesses momentos, o projeto foi estruturado e trabalhado com uma turma do $2^{\circ}$ ano do curso Técnico Integrado em Química do Instituto Federal de Goiás Câmpus Inhumas e com alunos voluntários do Programa Nacional de Integração da Educação Profissional com a Educação Básica na Modalidade de Jovens e Adultos - Proeja. Foram dois encontros de 3h cada ocorridas no segundo semestre de 2013 (Tabela 1).

Tabela 1. Detalhamento dos dois encontros.

\begin{tabular}{|c|c|l|l|l|}
\hline \multicolumn{2}{|c|}{ Aula } & \multicolumn{1}{c|}{ Atividades desenvolvidas } & \multicolumn{1}{c|}{ Principais temas } & $\begin{array}{c}\text { Observações (Diário } \\
\text { de campo) }\end{array}$ \\
\hline 1 & $04 / 12$ & $\begin{array}{l}\text { Utilização de vídeo sobre } \\
\text { Adulteração de combustíveis e } \\
\text { os problemas causados ao }\end{array}$ & $\begin{array}{l}\text { Formação, utilização } \\
\text { e aplicação do } \\
\text { petróleo; Etanol, e }\end{array}$ & $\begin{array}{l}\text { Participação ativa dos } \\
\text { alunos. }\end{array}$ \\
\hline
\end{tabular}


Revista Tecné, Episteme y Didaxis: TED. Año 2014, Número Extraordinario. ISSN Impreso: 0121-3814, ISSN web: 2323-0126 Memorias, Sexto Congreso Internacional sobre Formación de Profesores de Ciencias. 08 al 10 de octubre de 2014, Bogotá

\begin{tabular}{|l|l|l|l|l|}
\hline & & $\begin{array}{l}\text { consumidor e discussão sobre } \\
\text { este tema envolvendo } \\
\text { também questões éticas e } \\
\text { sociais. Questionário sobre os } \\
\text { temas abordados na sala de } \\
\text { aula. }\end{array}$ & $\begin{array}{l}\text { seus diferentes tipos; } \\
\text { Impactos da } \\
\text { produção de etanol; } \\
\text { gasolina e seus } \\
\text { diferentes tipos, } \\
\text { octanagem, índices } \\
\text { de octanagem, Ciclo } \\
\text { de Otto e as } \\
\text { questões éticas e } \\
\text { sociais. }\end{array}$ & \\
\hline 2 & $05 / 12$ & $\begin{array}{l}\text { Experimentação sobre "teor } \\
\text { de álcool na gasolina". } \\
\text { Avaliação final. }\end{array}$ & $\begin{array}{l}\text { Densidade, } \\
\text { solubilidade, } \\
\text { polaridade e forças } \\
\text { intermoleculares. }\end{array}$ & $\begin{array}{l}\text { Participação dos } \\
\text { alunos e dificuldades } \\
\text { na compreensão de } \\
\text { alguns fenômenos } \\
\text { químicos. }\end{array}$ \\
\hline
\end{tabular}

\section{A Problematização Inicial na sala de aula}

No desenvolvimento da problematização inicial em sala de aula buscamos identificar através de perguntas desafiadoras o conhecimento dos estudantes sobre o tema proposto e de questões relacionadas ao assunto. O problema é algo que uma determinada pessoa não sabe resolver prontamente, desde então é preciso que essa pessoa reflita e idealize a respeito de qual sequência de etapas que irá seguir. Em alguns casos, uma situação problema pode representar um problema para um grupo de pessoa e em outros casos pode se constituir apenas como um mero exercício. Acreditamos que, com a mediação do professor, devemos considerar o problema como obtenção de conhecimentos que cultiva saberes cognitivos, desenvolvendo caráter social.

A problematização inicial foi desenvolvida com a colocação de algumas questões para verificar o que os alunos já sabiam, ou seja, os seus conceitos espontâneos (Tabela 2).

Tabela 2. Problemas propostos no início da aula 1.

Qual é a ideia que você tem sobre a adulteração dos combustíveis?

Como é feito o processo de adulteração da gasolina?

Por que se usa o etanol na adulteração da gasolina?

Quais as vantagens para os donos de postos em adulterar a gasolina?

Quais as desvantagens para o consumidor?

Qual é importância do petróleo? 
Revista Tecné, Episteme y Didaxis: TED. Año 2014, Número Extraordinario. ISSN Impreso: 0121-3814, ISSN web: 2323-0126 Memorias, Sexto Congreso Internacional sobre Formación de Profesores de Ciencias. 08 al 10 de octubre de 2014, Bogotá

Protesores de Ciencias. 08 al 10 de octubre de 2014 Bogotá

and

Como o petróleo é formado?

Quais são os produtos obtidos através do petróleo?

Porque o petróleo é denominado uma fonte de energia não-renovável?

Foi, então, solicitado aos alunos a exposição de suas opiniões sobre as perguntas. Os alunos, nesse momento, participaram ativamente das discussões. Ao se realizar a primeira pergunta, um tema que surgiu foi a ética e ação do profissional técnico em Química. Como esses profissionais devem se comportar frente a esse problema? Foi criada uma situação hipotética: Suponhamos que vocês estejam trabalhando em um posto de combustível e neste posto a gasolina está adulterada, vocês fariam um laudo informando que a gasolina está inadequada para o uso, ou vocês passariam um laudo falso? Nessa questão foram discutidas as problemáticas ambientais envolvidas e a ética da profissão dando ênfase ao curso "Técnico em química".

\section{Organização do Conhecimento}

Elaboramos um questionário que foi respondido (Tabela 3) por uma indústria sucroalcooleira localizada em Inhumas - Brasil, a Centroálcool. Apresentamos os dados obtidos aos alunos do curso, para contextualizar as discussões a partir de uma temática específica da região.

Tabela 3. Entrevista feita na indústria sucroalcooleira em Inhumas - Goiás - Brasil.

\begin{tabular}{l} 
1)Qual a data da instalação da Indústria na cidade de Inhumas? \\
A indústria se instalou na cidade de Inhumas no ano de 1983. \\
\hline 2) Qual a produção anual de etanol? \\
A produção anual de etanol é 70.000 .000 litros. \\
\hline 3) Quantos funcionários a indústria possui? \\
A indústria possui 242 funcionários. \\
4) Porque a indústria veio para a cidade de Inhumas-Go? \\
Em 1981, vislumbrando o grande potencial da região, o empresário e produtor rural Roberto \\
Balestra formou, com um grupo de investidores, uma sociedade anônima para fundação da \\
primeira destilaria autônoma de Inhumas. Em 1984, realizou-se sua primeira safra. Para a \\
região e entorno a empresa passou a ser uma importante geradora de emprego e renda. \\
Desde meados de julho de 2012 , a administração da Centroálcool está a cargo do Diretor \\
Presidente Sr. Alceu Neto e do Diretor de Negócios Sr. Sandro Mascarin. \\
\hline
\end{tabular}


Revista Tecné, Episteme y Didaxis: TED. Año 2014, Número Extraordinario. ISSN Impreso: 0121-3814, ISSN web: 2323-0126

Memorias, Sexto Congreso Internacional sobre Formación de Profesores de Ciencias. 08 al 10 de octubre de 2014, Bogotá

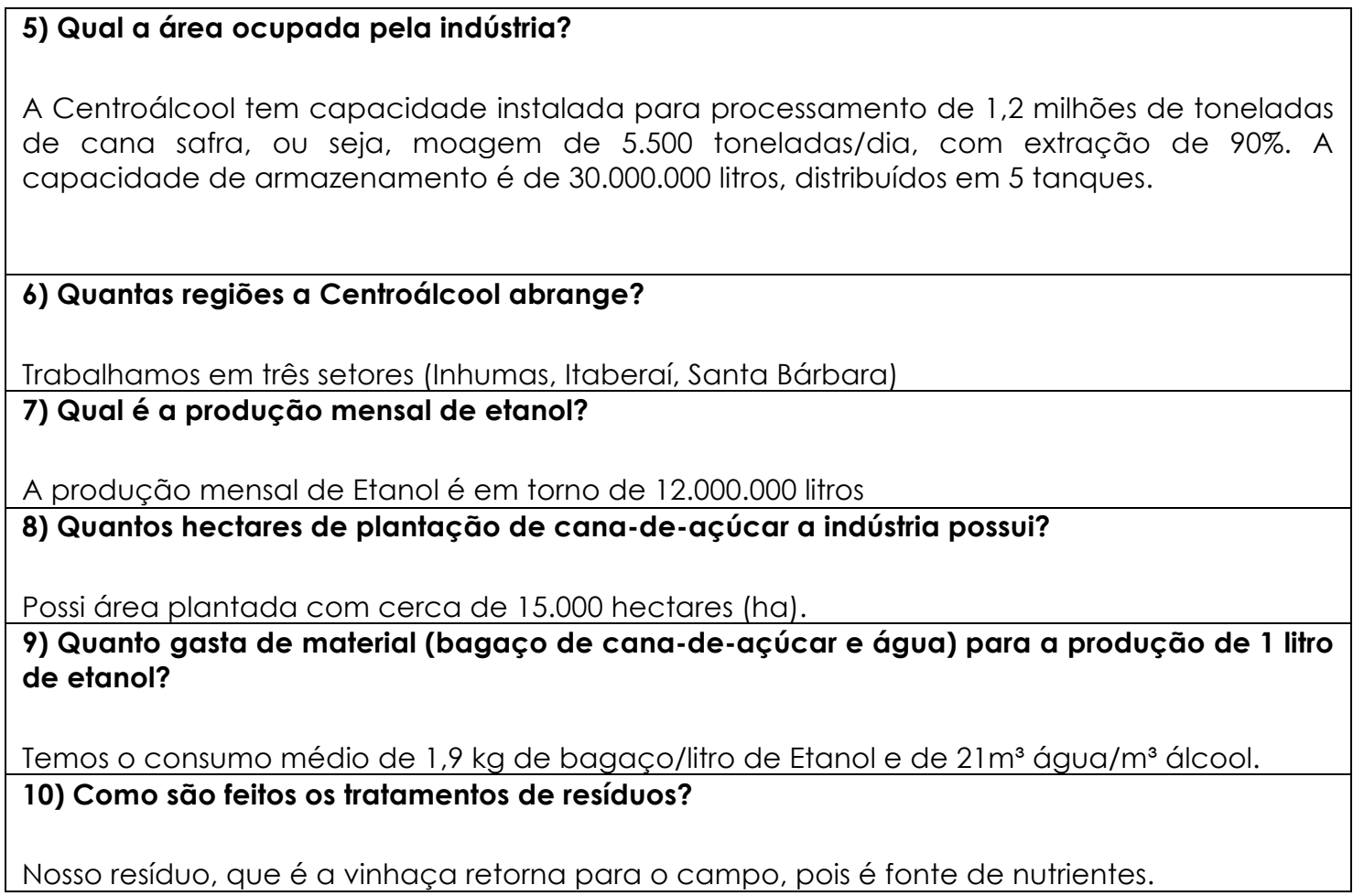

A organização do conhecimento foi desenvolvida em um segundo momento na aula 2. Nas aulas foram discutidos conceitos de petróleo (surgimento, composição química, utilização e aplicação), etanol (composição química, tipos de alcoóis para uso automotivo, etapas de produção, pontos positivos e negativos), gasolina (Composição química, octanagem, funcionamento do motor quatro tempos, tipos de gasolina). Além disso, durante as aulas e na abordagem dos conceitos também foram propostos problemas que despertassem a atenção dos alunos para os conteúdos abordados e contribuíssem no diálogo em sala de aula.

Foi apresentado aos alunos um vídeo ${ }^{5}$ sobre o tema que retratava a adulteração de gasolina nos postos de combustíveis e as consequências geradas pela adulteração. Foram colocadas imagens que caracterizaram conhecimentos como a imagem de um densímetro para saber se os alunos conheciam o equipamento e se já haviam observado nos postos (Figura 1). Nessa etapa foi discutida a utilidade do densímetro e que esse possibilita ao consumidor analisar a qualidade do álcool que está sendo vendido.

5 Vídeo apresentado aos alunos:

http://www.youtube.com/watch? $v=$ GyJ01EOSOxk\&feature=related 
Revista Tecné, Episteme y Didaxis: TED. Año 2014, Número

Extraordinario. ISSN Impreso: 0121-3814, ISSN web: 2323-0126

Memorias, Sexto Congreso Internacional sobre Formación de Profesores de Ciencias. 08 al 10 de octubre de 2014, Bogotá

Figura 1. Foto de um densímetro em um posto de combustível. Fonte: http://www.engenhariadacerveja.com.br/category/engenharia/

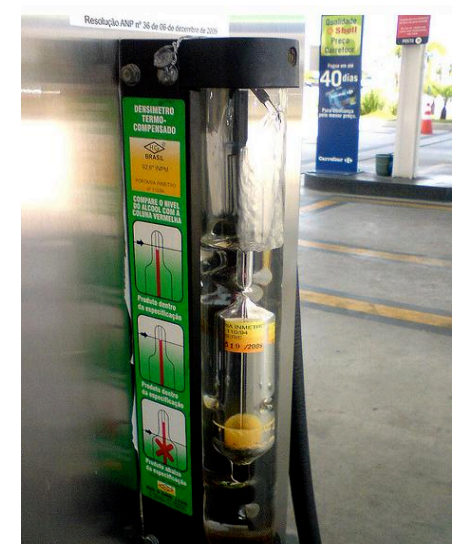

Uma figura que mostra um trabalhador em um canavial também foi utilizada (Figura 2). A ideia foi provocar a discussão quanto às condições de trabalho dos cortadores de cana, para problematizar, promover o debate e a reflexão sobre pontos que muitas vezes são omitidos no processo de produção do etanol.

Figura 2. Foto de um trabalhador cortando cana. Fonte: http://marcelaspoonnie.blogspot.com.br/

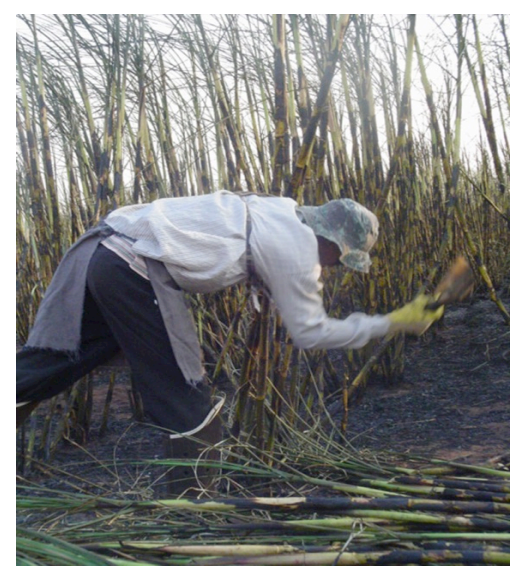

Um experimento investigativo sobre "Teor de álcool na gasolina" para analisar a qualidade da gasolina de alguns postos de combustível também foi feito. $O$ 
Revista Tecné, Episteme y Didaxis: TED. Año 2014, Número Extraordinario. ISSN Impreso: 0121-3814, ISSN web: 2323-0126

Memorias, Sexto Congreso Internacional sobre Formación de Profesores de Ciencias. 08 al 10 de octubre de 2014, Bogotá

objetivo dessa atividade foi discutir um experimento simples que eles poderiam utilizar para determinar a qualidade da gasolina que estavam adquirindo.

\section{Aplicação do conhecimento}

Essa etapa compreendeu a verificação do nível de aprendizado dos conhecimentos científicos vinculados aos conhecimentos já adquiridos pelos alunos. Ela ocorreu durante as duas aulas, desde a introdução de perguntas problematizadoras, para os alunos utilizarem seus conhecimentos, até a avaliação final. Para avaliar os conhecimentos dos alunos foi proposta uma narrativa a partir de uma pequena história estabelecida para os alunos darem sequência (Tabela 4).

Tabela 4. Avaliação final para a aplicação do conhecimento

Pedro sempre abasteceu seu carro no Auto Posto Inhumas Brasil. Porém, no decorrer do tempo, seu carro começou apresentar problemas no motor e alto consumo de gasolina. Diante disso, ficou desconfiado que a gasolina do posto estava adulterada. Ele conhecia um técnico em Química que sabia fazer a análise da gasolina e pediu ajuda para analisar a gasolina. Imagine que você seja esse técnico. Continue essa história. Você deverá levantar hipóteses e realizar procedimento que ajude Pedro a identificar se a gasolina do posto está adulterada ou não, explicando para ele todo o processo de análise. Use argumentos que foram discutidos durante as aulas. Caso seja identificado à adulteração o que você faria? Não se esqueça de apresentar argumentos da química considerando as questões sociais, econômicas e éticas.

Lembre-se uma narrativa deve conter início, meio e fim, e ter no mínimo 20 linhas.

A avaliação ocorreu individualmente e possibilitou aos alunos mobilizarem os conhecimentos adquiridos nos dois dias de discussão para terminar a história.

Diante dessa discussão, podemos observar que o papel do professor é primordial no desenvolvimento dessas atividades, pois ele será o mediador. Assim, se faz importante discutirmos especificamente sobre as dificuldades e desafios enfrentados pelos mesmos na inserção dessas atividades, seja da contextualização, seja da experimentação investigativa, ambas por meio dos momentos pedagógicos, no cotidiano da escola.

Com a implementação do projeto observamos que o tema proposto "Adulteração de combustíveis", causou impacto principalmente nas questões sociais, éticas, políticas e científicas. A participação ativa dos alunos nas três etapas possibilitou esse diagnostico. 
Revista Tecné, Episteme y Didaxis: TED. Año 2014, Número

Extraordinario. ISSN Impreso: 0121-3814, ISSN web: 2323-0126

Memorias, Sexto Congreso Internacional sobre Formación de Profesores de Ciencias. 08 al 10 de octubre de 2014, Bogotá

\section{Referências Bibliográficas}

Cachapuz, A.; Gil-Pérez, D.; PessoA, A. M.; Praia, J.; Vilches, A. A necessária renovação do ensino das Ciências. São Paulo: Cortez, 2005.

Delizoicov, D. Conhecimento, tensões e transições. 214f. Tese (Doutorado em Educação) - Faculdade de Educação, Universidade de São Paulo, São Paulo, 1991.

Delizoicov, D.; Angotti, J. A. P.; Pernambuco, M. M. Ensino de Ciências: fundamentos e métodos. São Paulo: Cortez, 2002.

Freire, P. Pedagogia do oprimido. 42.ed. Rio de Janeiro: Paz e Terra, 2005.

Agradecimentos:

CNPq (Conselho Nacional de Desenvolvimento Científico e Tecnológico) 